\title{
Seeing red: The use of a biological stain to identify cooked and processed/damaged starch grains in archaeological residues
}

Jenna Weston

\author{
Australian Museum Business Services \\ 6 College St \\ Sydney NSW 2010 Australia
}

\begin{abstract}
Starchy plant foods are a major component in the diet of almost all peoples, particularly hunter-gatherers such as Aboriginal Australians. However, the archaeological preservation of such plants is rare, as is other direct evidence of plant use by past peoples. While analysis of starchy residues preserved on artefacts has gained acceptance as an effective method for identifying starchy plant use, it is very difficult using the standard morphological method to accurately identify starch grains that have been damaged by processing activities such as milling or cooking. Therefore, a method is presented for the identification of such damaged starch grains using the stain Congo Red, which dyes damaged (cooked or processed) but not undamaged starch. This method has been applied to identify cooking or milling activities in the subsistence of hunter-gatherers from south-east Queensland, Australia.
\end{abstract}

Keywords: Congo Red; starch grains; cooking; residue analysis; bevel-edged artefacts; south-east Queensland.

\section{Introduction}

The following paper presents the results of a feasibility study that was initially undertaken as part of an Honours thesis at the University of Queensland (Lamb 2003) under the supervision of Dr Tom Loy. This work resulted in the establishment of a new method for determining cooking in archaeological plant residues, which was published (Lamb and Loy 2005) and then presented at the 2005 Australasian Archaeometry Conference. This paper provides a summary of the methods and archaeological applications published by Lamb and Loy (2005), and expands upon the 2005 publication with new data on taphonomic controls and additional images. It is published in this forum subsequent to Dr Loy's death, with acknowledgement for his role in developing the method. 


\section{Background}

As has been established by a number of studies (e.g., Brand and Cherikoff 1985; Gould 1969; Latz 1995; Latz and Griffin 1978; Lee 1965, 1968; Meehan 1989; O'Connell et al. 1983; Peterson 1978), plant foods, particularly starchy plants, are a major part of people's diets. This is especially true for hunter-gatherers, such as Aboriginal Australians (Beck et al. 1989:6; Kaberry 1935:6; Mountford 1960; Peterson 1973). However, these plants are often not preserved in whole form in the archaeological record, particularly in Australia, and direct evidence of plant use by past peoples is also rare (Hather 1991:661; Meehan 1989:14; Pearsall 2000:153; Piperno and Holst 1998:765; Therin et al. 1999:439). Residue analysis, particularly analysis of starchy residues preserved on artefacts, has now become accepted as an effective method for identifying past plant use and starch grains, which seem to be fairly prolific in archaeological plant residues, can also allow the identification of cooking in residue evidence (Babot 2003; Barton et al. 1998; Fullagar 1998; Loy 1994; Loy et al. 1992; Piperno and Holst 1998; Torrence and Barton 2006).

\section{Starch}

Starch grains have a very regular structure of amylose and amylopectin layers (Badenhuizen 1965:81; Banks and Greenwood 1975:242; Cortella and Pochettino 1994:172; Loy 1994:89; Reichert 1913:89). This structure imparts the distinctive 'cross' that they exhibit when viewed microscopically in cross-polarised light, which will rotate radially when the polariser plate is rotated. This cross effect is also displayed by faecal spherulites, ooliths, some coccoliths, some avian and reptile uric acid spheres, some plant calcium oxalates and some other biologically precipitated compounds, but each of these has a much higher refractive index than starch, so viewing residues through a low refractive index medium like water makes these compounds almost invisible owing to excessively high relief (Banks and Greenwood 1975; Canti 1998; Loy 1994; Reichert 1913).

The regular structure of starch is altered by cooking, however, a feature which allows the identification of cooking via residue analysis. This is important because it can provide additional evidence that an artefact was used in human subsistence-related activities, namely the cooking of plant foods, which is a uniquely human activity. Other evidence of the human subsistence use of an artefact may include the presence of other food residues from plants, use wear, and ethnohistoric accounts of certain stone tools being used to prepare food.

The known effects of cooking on starch include mainly swelling and loss of the regular structure of the grains, with a corresponding loss of the extinction cross (Banks and Greenwood 1975; Hall et al. 1989; Loy 1994). This is a process known as gelatinisation, and it occurs when the grain is in the presence of moisture and is heated at temperatures greater than $30^{\circ} \mathrm{C}$. During this process, the hydrogen bonds linking the amylose chains are progressively broken and the grain absorbs water, which is what causes it to swell. The temperature and rate at which a grain gelatinises depend on factors such as the presence of additives like glucose or mineral salts, and the size and shape of the starch grain. This loss of the cross effect in cooked starch grains makes it very difficult to identify them accurately using the standard morphological method, because their appearance depends on the stage of gelatinisation, and at some point in this process the cross becomes completely invisible (Banks and Greenwood 1975; Loy 1994; Reichert 1913).

One way to address this problem of how to identify cooked starch lies in the effects of cooking on starch grains. The loss of the structure from the breaking of their hydrogen bonds, and the swelling caused by absorption of water, should allow cooked grains to absorb certain stains where raw and undamaged starch grains, which are hydrophobic, will not.

\section{Congo Red}

Congo Red (CI 22120, CI name 'Direct Red 28'; empirical formula $\mathrm{C}_{32} \mathrm{H}_{22} \mathrm{~N}_{6} \mathrm{O}_{6} \mathrm{~S}_{2} \mathrm{Na}_{2}$ ) is a water-soluble dye and a suspected carcinogen, which depends on linear hydrogen bonding for staining (Conn and 
Lillie 1969). This stain has been used in other studies as a general contrast stain for cellulose, amyloid fibrils and agricultural starch products (Chou et al. 2001; Conn and Lillie 1969; Ramesh and Thranathan 1999). However, it stains proteins like amyloid fibrils only in acid or alkaline conditions, so at a neutral pH only starch and cellulose will stain (Badenhuizen 1965:86; Conn and Lillie 1969; Cortella and Pochettino 1994; Khurana et al. 2001 [pH2-4]; Loy 1994:92; Mehta and Rajput 1998 [pH3.5]; Reichert 1913). Congo Red appears to react with the amylose in starch, which is exposed when grains are damaged by structure loss and swollen with water, as when they have been cooked.

The amylose in starch is based on the same monosaccharide molecule as cellulose (Figure 1). However, as Figure 1 shows, the molecule is bonded in a different way in each. Therefore both cellulose, and starch grains that have broken bonds, will stain with Congo Red, but their appearance and structure are visibly different, so they can be differentiated under the microscope.

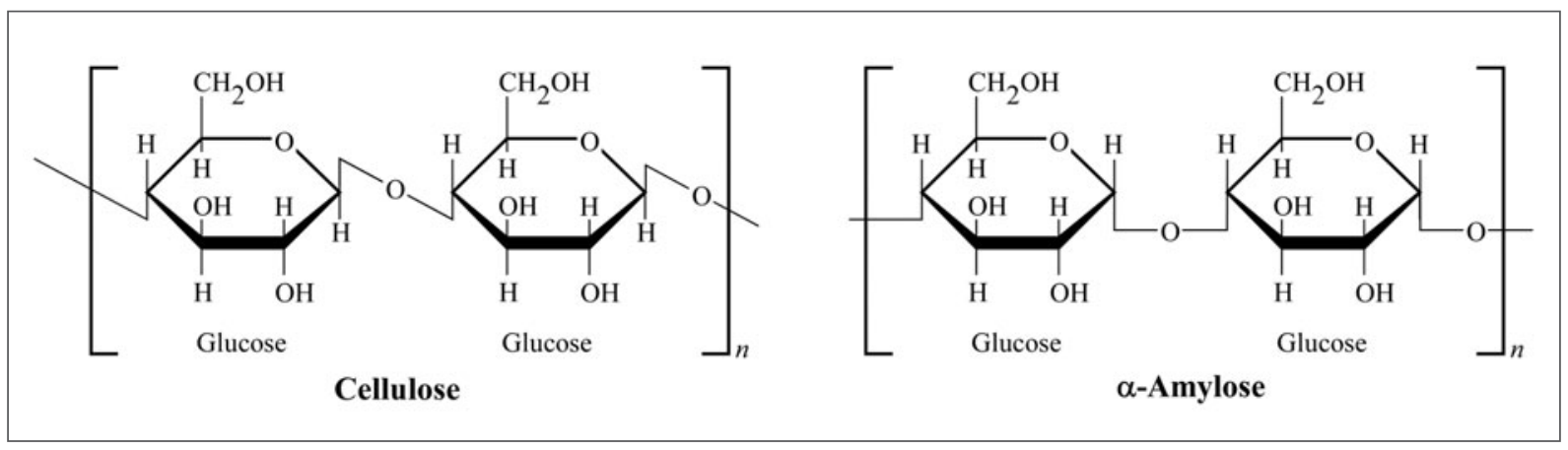

Figure 1. Primary structure of cellulose and $\alpha$-amylose (from starch). n may be several thousand (after Voet and Voet 2004:365-6).

\section{Methodology}

In order to test the effects of the stain, it was necessary to use it on both experimental and archaeological residues. For the experimental phase, three plants were chosen which each had high starch content and were present in south-east Queensland, and for all of which there are ethnohistoric accounts of their having been cooked and then pounded between stones by Aboriginal people in this area. These plants were Alocasia macrorrhiza (elephant ear; see Brown 1893, Roth 1901, Thozet 1866), Blechnum indicum (Bungwahl fern; see Threlkeld 1825, Watkins 1891), and Castanospermum australe (Moreton Bay chestnut; see Banfield 1908, Moore [cited in Maiden1900], Roth 1901). The starchy root or seed from each of these plants was taken, and raw samples were smeared onto slides. The remaining root/seed was then cooked in an electric frypan filled with sand (to simulate roasting as if in a fire), and cooked samples were smeared onto slides. Another specimen of the three plants was then taken, and part of each was processed when raw by pounding between two stones, then another part of each was processed in the same way after having been cooked in a fire (on different days and different places in the fenced area of the University of Queensland's TARDIS excavation site, so as to avoid contamination). After the residues had dried, samples were extracted from the experimental stones and placed onto microscope slides using the procedure outlined in Lamb and Loy (2005:1435 [Table 1]).

After microscopic examination of the characteristics of each of the raw, cooked, raw and processed, and cooked and processed starch samples, each was then stained with Congo Red, using the procedure outlined in Lamb and Loy (2005:1435 [Table 1]), being very careful to take precautions against the possible carcinogenic properties of the stain. This was achieved mainly by wearing a lab coat and non-starch-powdered gloves, and sealing the slide covers once the stain was applied. The Congo Red solution used was originally made up by dissolving $50 \mathrm{mg}$ of the powder into $50 \mathrm{ml}$ of water; in this 
situation face masks and eye goggles were worn in addition to the lab coat and gloves. The solutions applied to the slides all had the low refractive index of water, to avoid confusion with the cross effects given by non-starch residues, as previously mentioned.

Archaeological residues were initially taken from three bevel-edged artefacts from the Southern Curtis Coast (Figure 2). These artefacts (Figures 3-5) were provided by Dr Sean Ulm, having been collected by him during his PhD research (Ulm 2006). A further archaeological residue was recovered from a fourth bevel-edged artefact which was excavated from a shell midden on the Gold Coast (Robins et al. 2005).

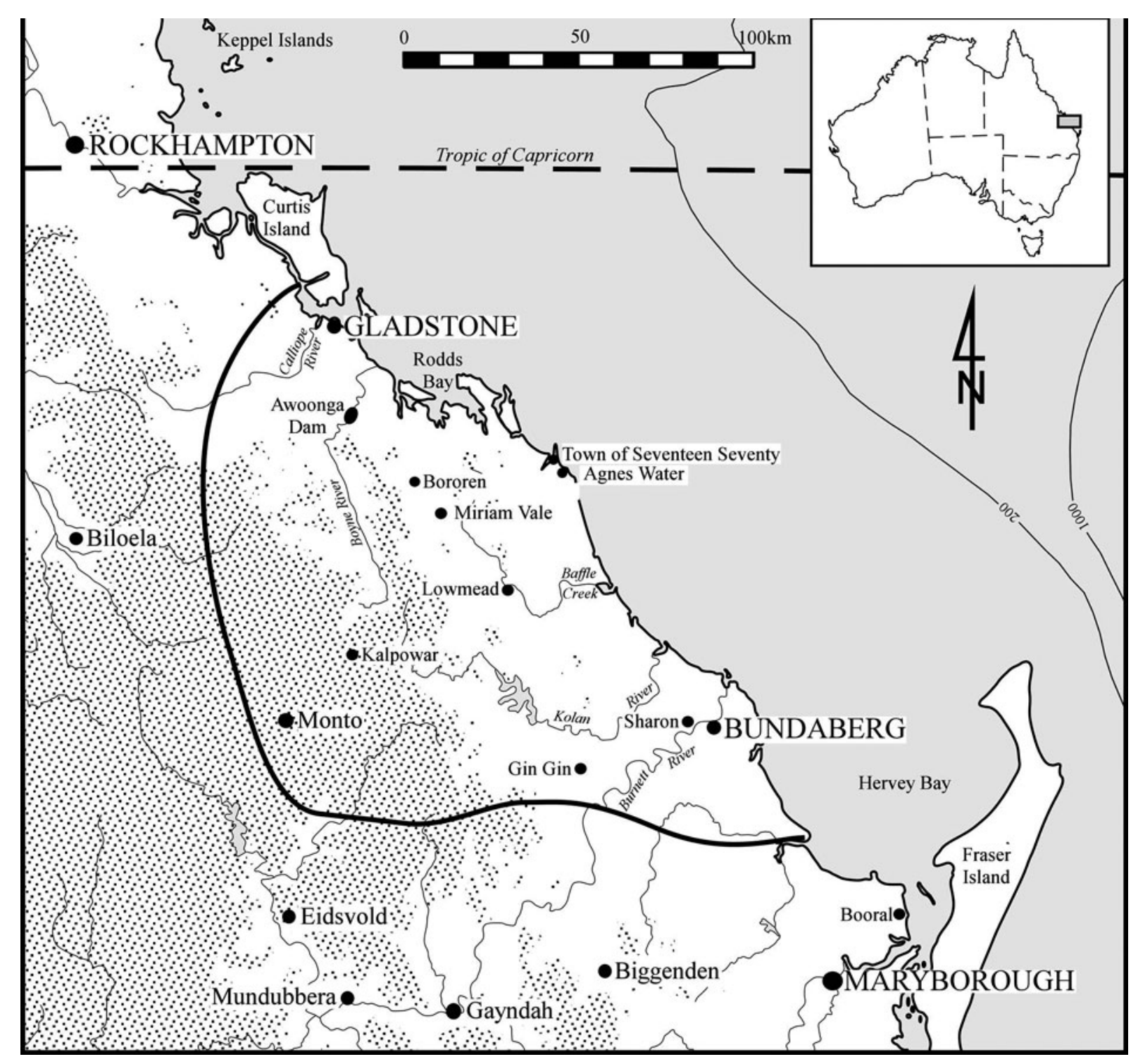

Figure 2. Location of Southern Curtis Coast from where the initial three archaeological artefacts were recovered (Ulm 2006:15). 


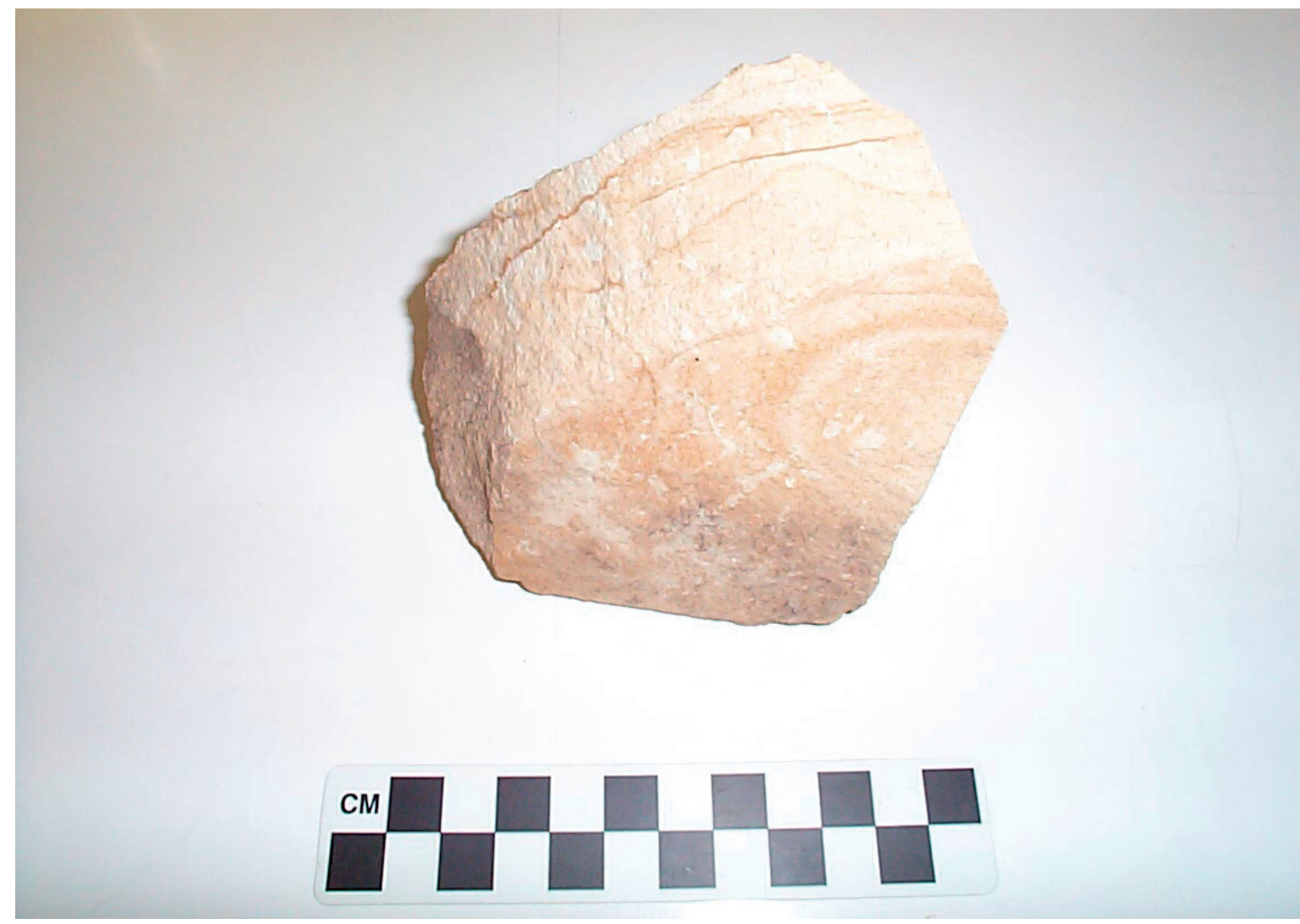

Figure 3. Bevel-edged artefact 1, surface-collected from an eroding creek section at Eurimbula Site 1 (ES1) on the western bank of Round Hill Creek as part of the Gooreng Gooreng Cultural Heritage Project (GGCHP), on 9 March 1999. ES1 is an extensive open midden complex located in Eurimbula National Park, with deposits dating to the last 3,200 years (Ulm 2006:177).

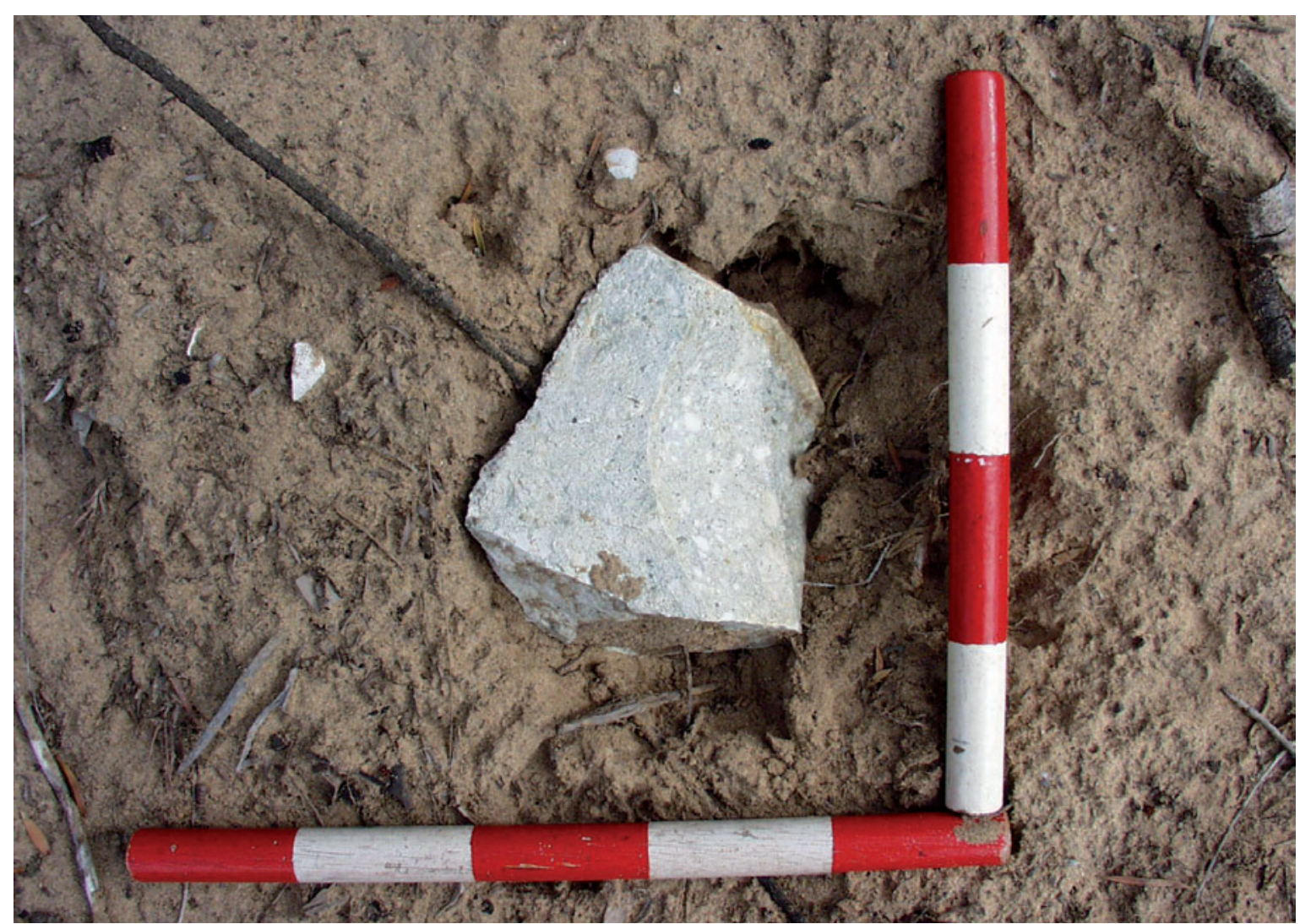

Figure 4. Bevel-edged artefact 2, surface-collected from an eroding creek section at ES1 on the western bank of Round Hill Creek as part of the GGCHP, on 3 June 2001. Scale $=5 \mathrm{~cm}$ units. 


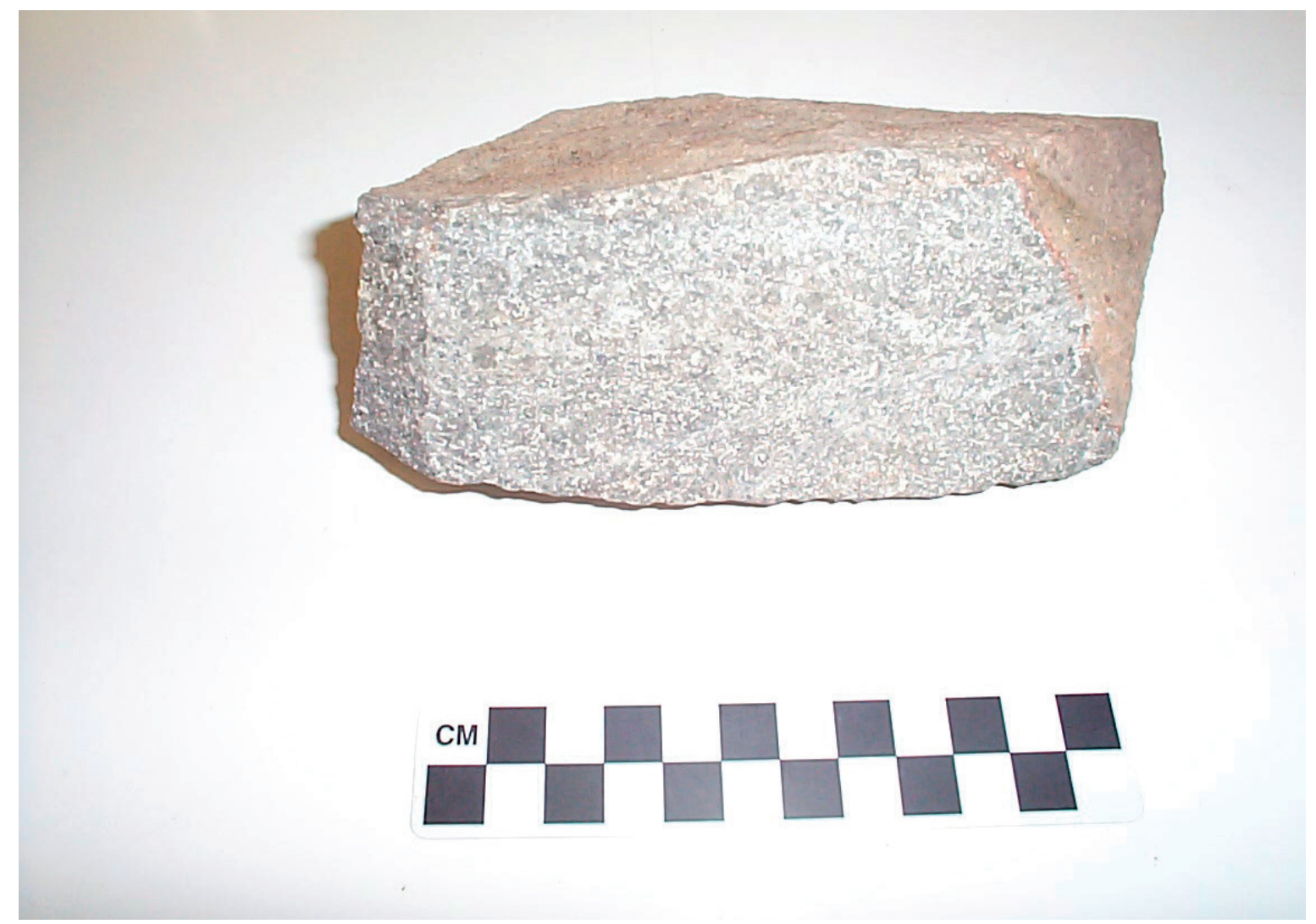

Figure 5. Bevel-edged artefact 3, found $20 \mathrm{~m}$ from Squares 0 and $P$ at the Ironbark Site Complex (ISC) as part of the GGCHP, on 13 February 1998. ISC is an extensive stone quarry/shell midden site complex located on the lower southern bank of Middle Creek estuary, with deposits dated to the last 500 years (UIm 2006:131).

Residues were extracted from multiple positions on each artefact, mainly along the edges and on the flat, bevelled surface. All archaeological residues were extracted using the procedure outlined in Lamb and Loy (2005:1436 [Table 2]).

After examining each residue slide and noting the presence and characteristics of the starch (and other plant residues), each slide was stained using the same procedure as for the experimental residues (Lamb and Loy 2005:1435 [Table 1]).

\section{Results}

Samples of starch from the processed raw plants tended to stain light red in regular light and retained their cross effect in cross-polarised light, often as four dark points in their outline (Figure $6 a$ and b). Partially-cooked grains may also have this appearance when stained, but would have swollen somewhat, so if the species of the plant residue is known, this distinction in activity may be determined. 


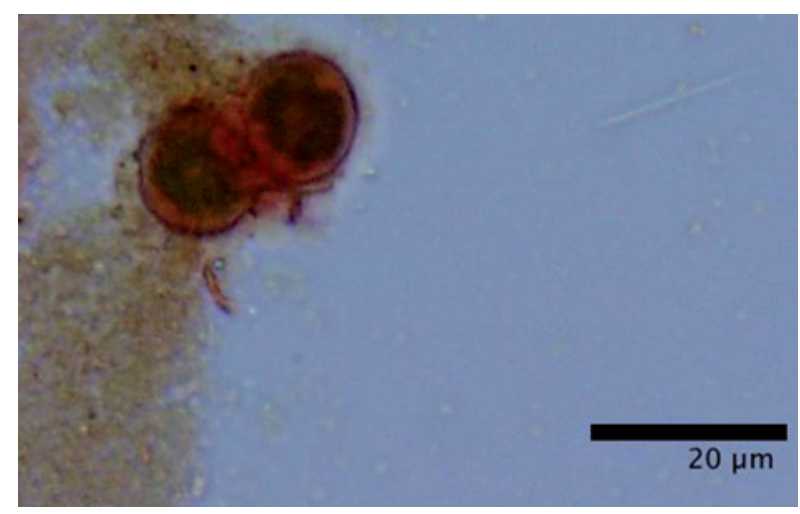

6 a.

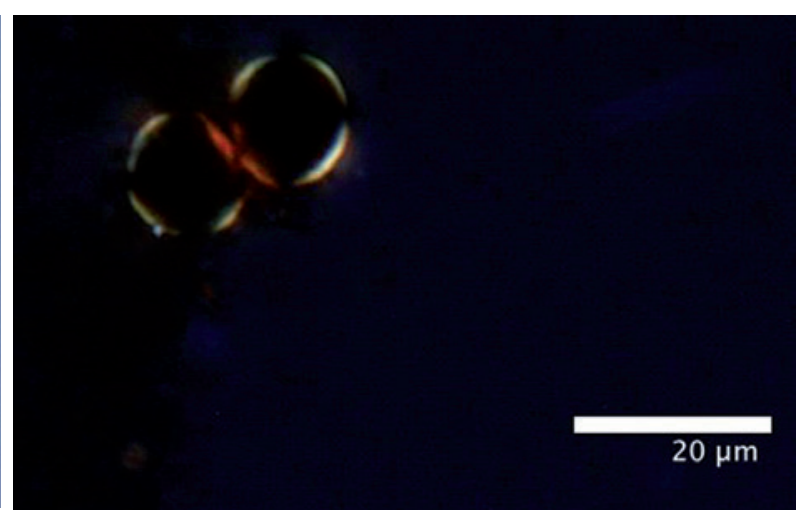

$6 b$.

Figure 6. Damaged starch grains from raw, processed Alocasia macrorrhiza sample, 400x magnification, stained (a) transmitted light (b) cross-polarised transmitted light.

The raw, unprocessed starch samples did not stain, unless they had been unintentionally damaged during the experiments. However, the well-cooked, gelatinised grains stained bright red, often with either an orange-red or green-gold glow. These grains were not seen in regular light without staining, but application of Congo Red revealed that they had swollen quite dramatically. In the instance of Moreton Bay chestnut (seen in Figures 7-8), the grains had swollen to around ten times their original size. Some pitting, layering and cracking can also be seen in the swollen grains (Figure 8). Generally, cooked grains did seem to retain enough of their structure for them to maintain their primarily round or oval shape, although extensive swelling associated with heating appears to be able to change the morphology of grains somewhat (e.g. from round to oval-shaped; see Figures 7-8) and for a modified cross to appear, as four darker points in their outline, when viewed in cross-polarised light.

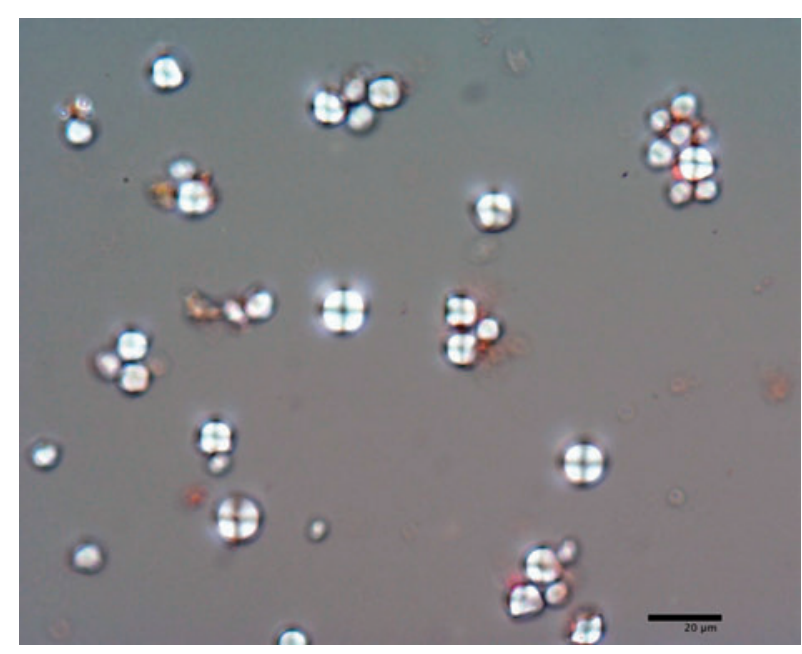

Figure 7. Starch grains from raw Castanospermum australe sample (cross-polarised transmitted light, 400x magnification, stained). Scale bar 20um.

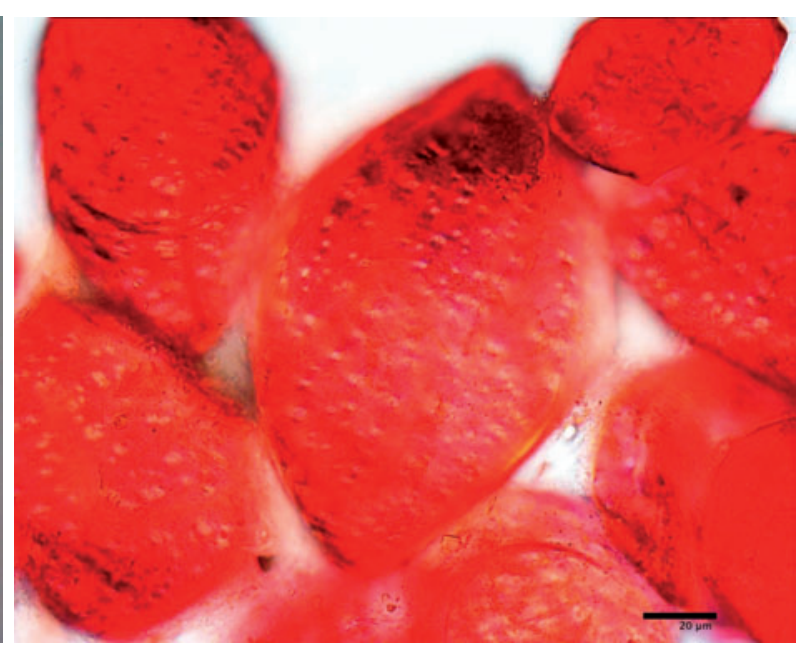

Figure 8. Starch grains from cooked (astanospermum australe sample (transmitted light, 400x magnification, stained). Scale bar 20um. 
Substantial quantities of both stained and unstained starch grains were seen in the archaeological residues. The unstained grains were interpreted as being raw and unprocessed, or not heavily processed. The stained grains were considered to belong to one of two categories. Figures 9 ( $\mathrm{a}$ and b) and 10 (a and b) show some grains that are thought to have been processed to some extent but were uncooked, because they stained slightly red but retained their extinction cross. In contrast, Figures 11-15 show stained grains argued to have been cooked, because they stained bright red in regular transmitted light, and had only a modified cross as four dark points in the outline of the grain when viewed in cross-polarised light.

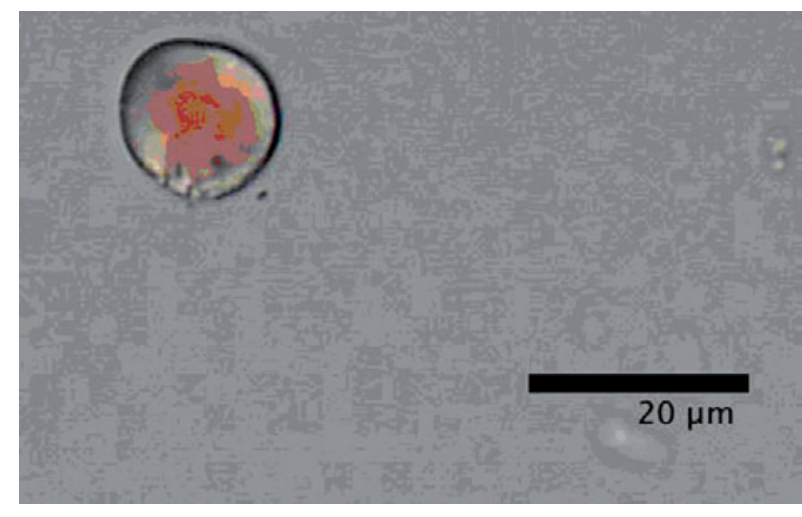

9 a.

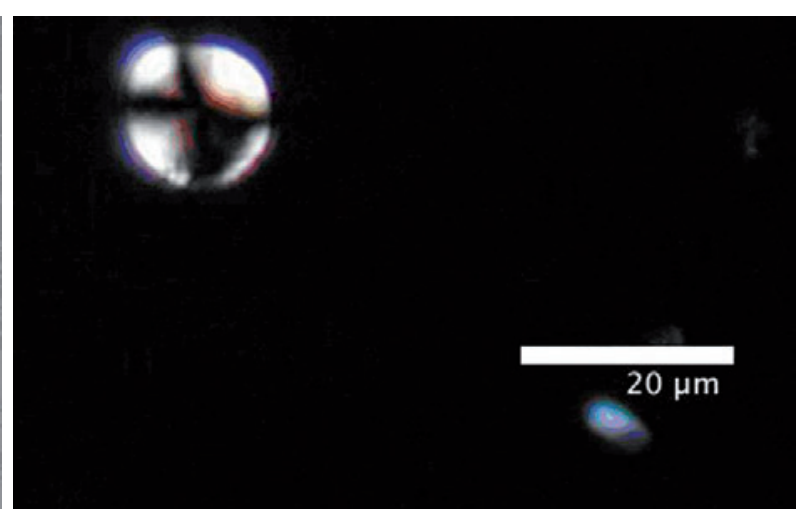

$9 b$.

Figure 9. Damaged starch grain from bevelled face, Artefact \#2, 400x magnification, stained (a) transmitted light (b) cross-polarised transmitted light.

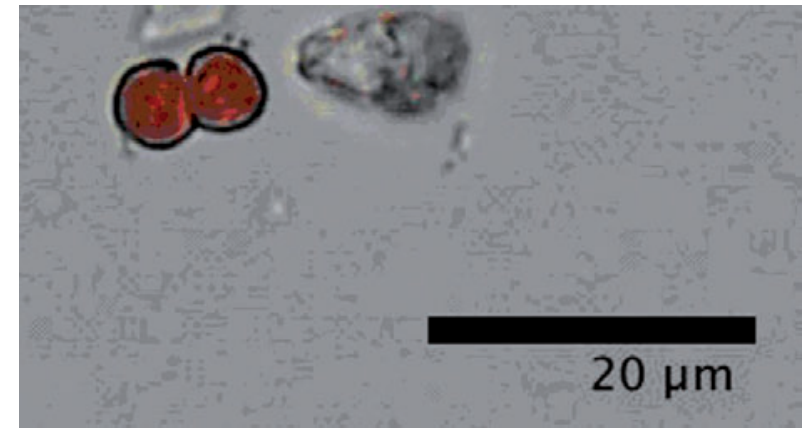

$10 \mathrm{r}$.

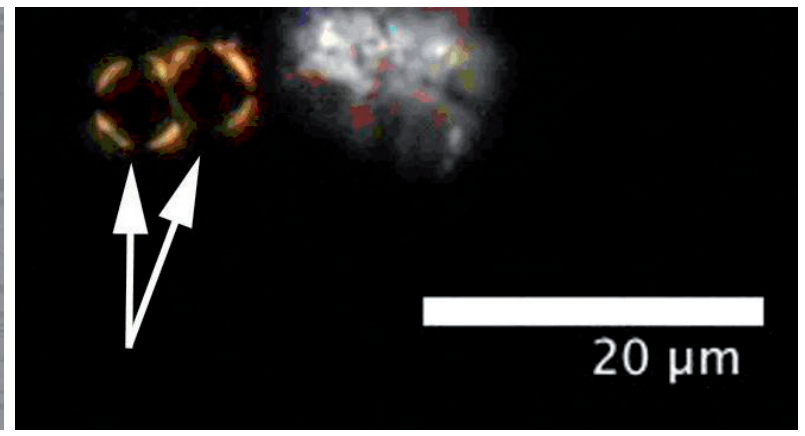

$10 b$.

Figure 10. Starch grains (arrows in B) from bevelled face, Artefact \#3, 400x magnification, stained (a) transmitted light (b) crosspolarised transmitted light.

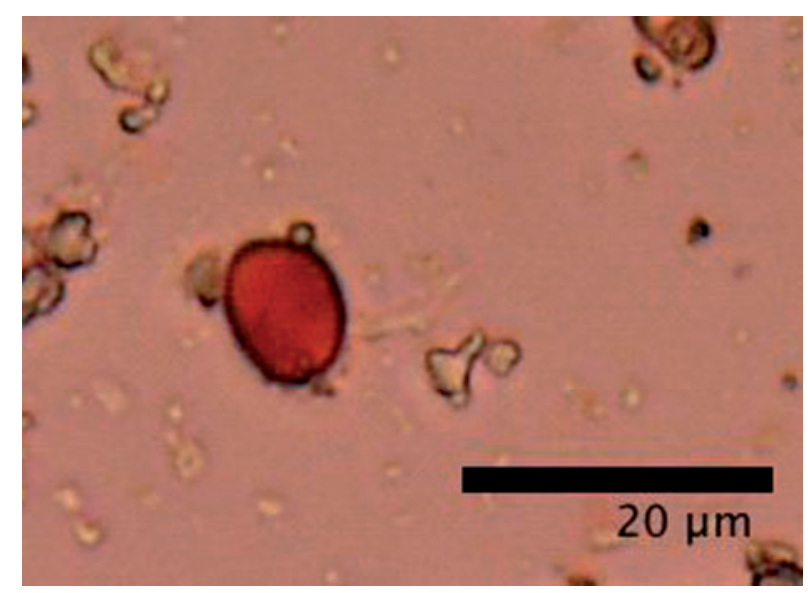

11.

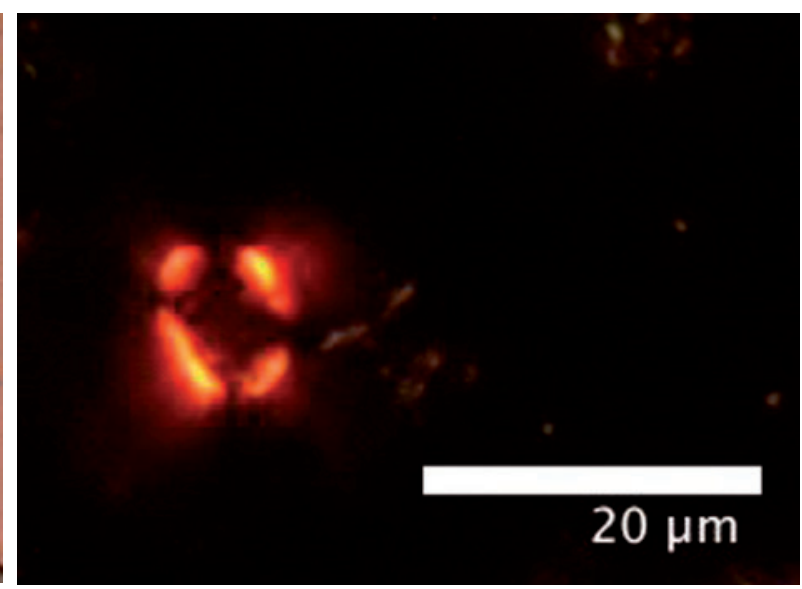

$11 b$.

Figure 11. Starch grain from Artefact \#2, 400x magnification, stained (a) transmitted light (b) cross-polarised transmitted light. 


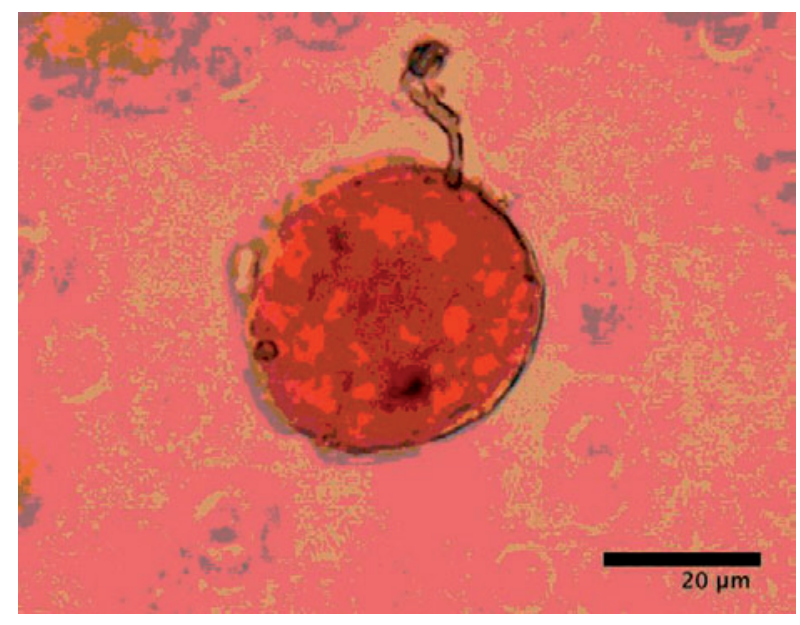

12a.

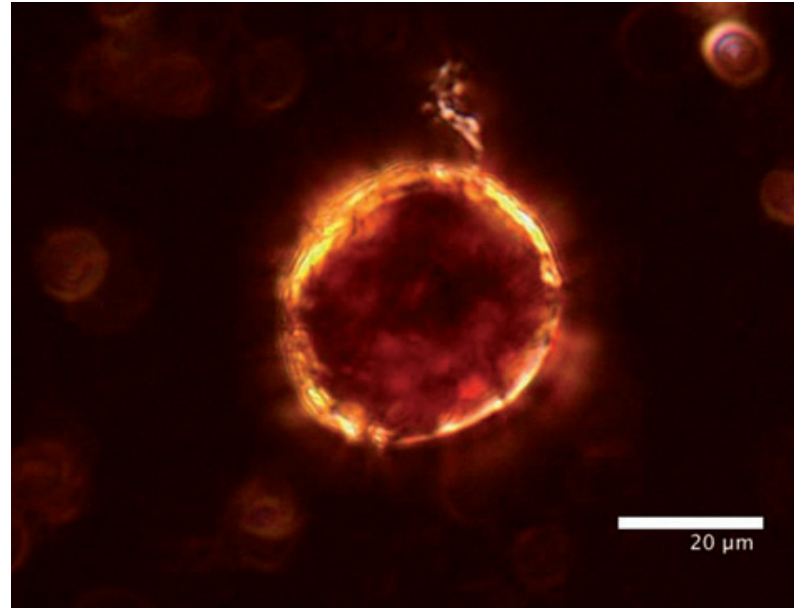

$12 b$.

Figure 12. Gelatinised starch grain from Artefact \#2, 400x magnification, stained (a) transmitted light (b) cross-polarised transmitted light.

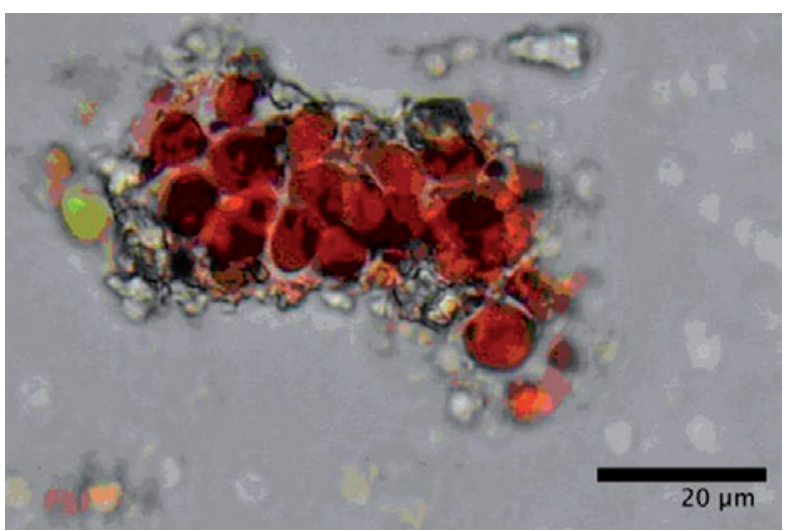

Figure 13. Group of starch grains from sloped face, Artefact \#1 (transmitted light, 400x magnification, stained).

The fourth archaeological artefact produced plant-dominated residues, with predominantly small starch grains (approximately 10-15 microns in diameter), many of which stained and hence were interpreted as having been processed or cooked. The grain shown below in regular transmitted (Figure 16a) and cross-polarised light (Figure 16b) was assessed as having been cooked because it was stained bright red with a modified cross in the outline.

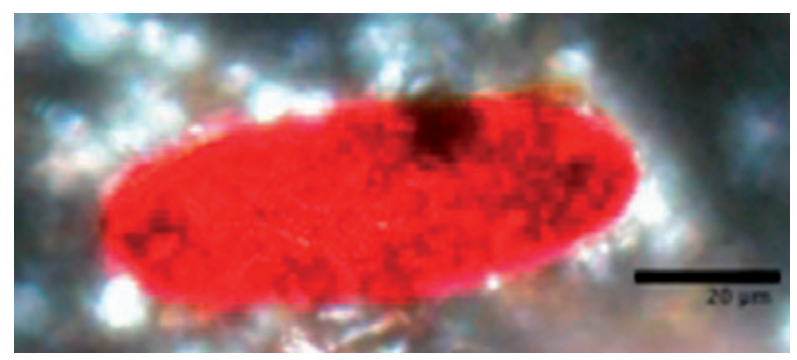

Figure 14. Gelatinised starch grain from bevelled face, Artefact \#1 (cross-polarised transmitted light, 400x magnification, stained).

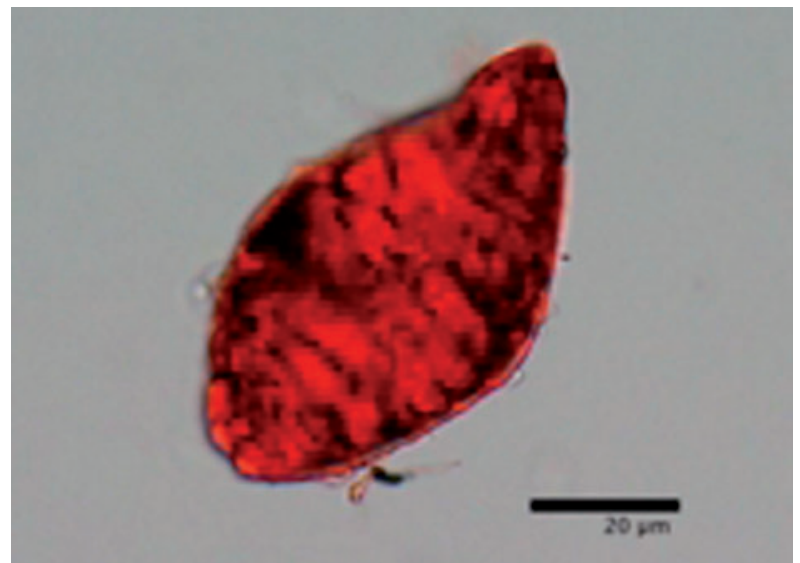

Figure 15. Gelatinised starch grain from bevelled face, Artefact \#2 (transmitted light, 400x magnification, stained). 


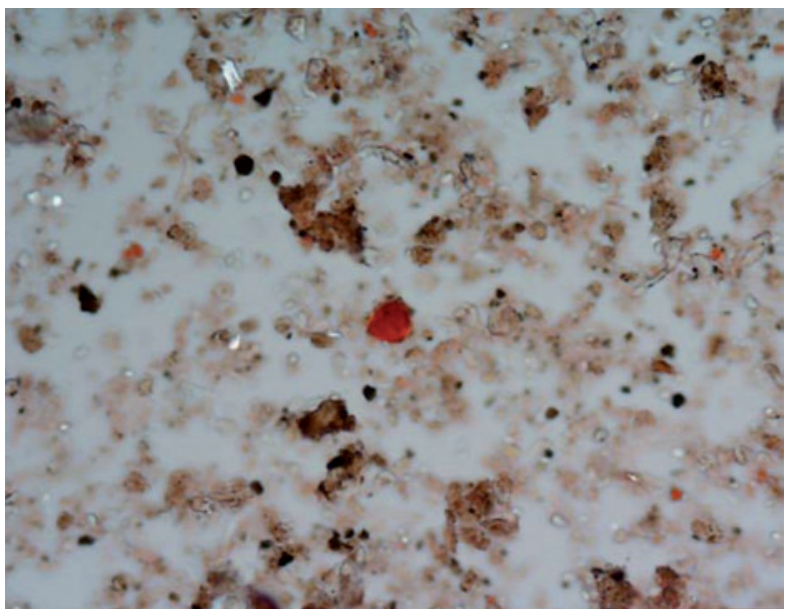

16 a.

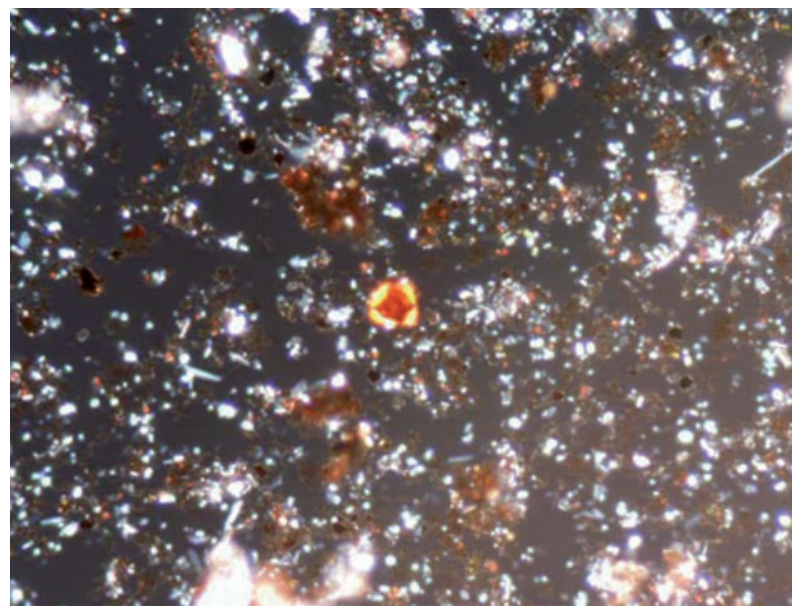

$16 \mathrm{~b}$

Figure 16. Damaged (12um) starch grain, 400x magnification, stained (a) transmitted light (b) cross-polarised transmitted light.

Congo Red was observed to stain sclereids, tracheids, parenchymal tissue (Figure 17), wall thickenings, bordered pits (Figure 18) and cellulose. However, while these stained red in regular light, they usually appeared green or yellow in cross-polarised light, rather than red as was the case with the starch grains.

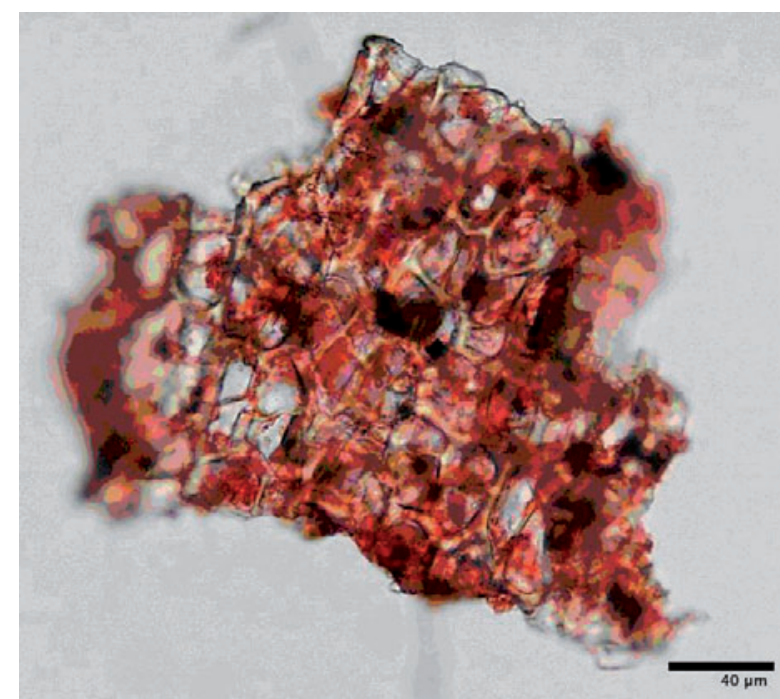

Figure 17. Parenchyma tissue from stained section, Artefact \#2 (transmitted light, 200x magnification, stained).

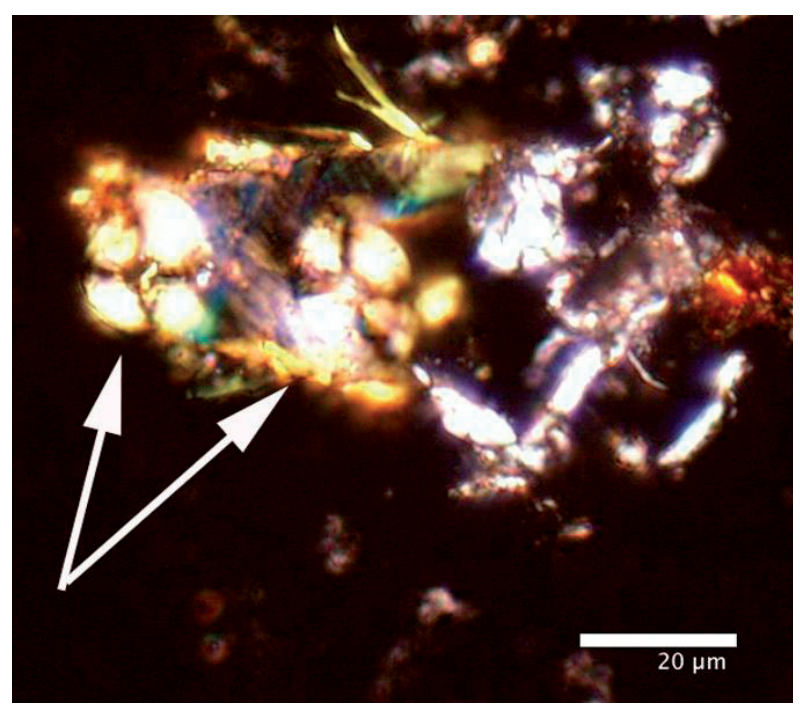

Figure 18. Bordered pits (arrows) from Artefact \#2 (cross-polarised transmitted light, 400x magnification, stained).

\section{Discussion of Results}

Nothing similar in appearance to the gelatinised starch grains was observed to stain in the same way, and the stained starch grains that were concluded to have been damaged through processing were also quite distinctive in appearance. It was therefore concluded that each artefact had most likely been used to process a starchy plant or plants, at least one of which was cooked to some extent before being processed. The described studies have therefore ascertained that Congo Red appears to be a feasible method for identifying cooking and processing in past societies. 


\section{Taphonomic Studies}

Several brief taphonomic studies were also conducted to ascertain the extent of non-processing-related starch contamination on the stone artefacts. The possibility of ground contamination was tested by trampling a sterile (i.e. newly manufactured) tool into the ground where experimental processing was undertaken. Soil samples examined before processing revealed almost no starch grains; after processing starch was present in the soil and hence was a potential source of contamination if tools were trampled into the soil. Starch grains, plant material and dirt were recorded on the tools which were trampled into soil of the processing area, although only $23 \%$ of the total recorded on the processing tools was present (see Table 1, Tool Type 2).

\begin{tabular}{|lll|}
\hline Tool type & $\begin{array}{l}\text { Number of recorded } \\
\text { starch grains }\end{array}$ & $\begin{array}{l}\text { Percentage compared } \\
\text { with processing tools }\end{array}$ \\
\hline 1. Experimental processing tools & 146 & N/A \\
\hline 2. Ground contaminated tools & 19 & 13.01 \\
\hline 3. Touch contaminated tools & 34 & 23.29 \\
\hline 4. Air contamination slide & 3 & 2.06 \\
\hline
\end{tabular}

Table 1. Quantities of Alocasia macrorrhiza starch grains (raw and cooked) recovered from processing, trampling and touch-test experiments, and air contamination. Values were calculated using one unstained microscope slide for each activity.

The possibility of contamination through touch was tested by handling clean experimental tools after the user had processed each plant (Table 1, Tool Type 3). On these tools, starch grains and plant material were also seen and the quantity was about $13 \%$ of that seen on processing tools (see Table 1). All tools were subjected to the contamination mechanism for the same amount of time (ten seconds), but it is likely that more grains would have been transferred to the tools if they were subject to a longer period of exposure or handling.

Lastly, the possibility of air contamination was tested by placing a clean microscope slide in the open air near the place where processing occurred; only three starch grains were found on this slide.

Therefore, it is concluded that contamination of tools can occur through handling and trampling. Use-wear analysis provides a potential method for identifying when this is the case with archaeological tools preserving residues.

It is possible that natural attacks on starch by enzymes in biologically active soils may cause damage that would stain with Congo Red. This possibility has not been tested as part of the current research. However it seems unlikely that enzyme attack would swell the starch grains in the way that cooking does. Although it may be more difficult to distinguish processing damage from enzyme damage, use-wear analysis of tools should enable a better understanding of whether this may be the case. In both cases further experimental studies may provide useful insights into the potentially confusing effect of enzyme damage.

\section{Archaeological Implications}

The use of Congo Red when working with starchy residues from archaeological artefacts means that a cultural association may be more confidently made between the tool and its use in subsistence activity, particularly plant food preparation. This is because Congo Red only stains starch that has been damaged, whether the damage has occurred through processing or through cooking, or both, and does not stain undamaged grains. Therefore the use of Congo Red can make a significant contribution to the preponderance of evidence for human subsistence use of an artefact. 


\section{Possible Applications}

Congo Red may be useful in testing the accuracy of ethnohistoric accounts of starchy plant preparation, particularly those plants that need to be cooked or processed prior to consumption because they are toxic or unpalatable raw (for example, in Australia, cycads as well as Alocasia and Castanospermum australe). It may also be used to contribute to the debate on the origins of controlled fire use, by being applied to artefacts associated with early humans such as Homo erectus, and detecting whether these artefacts retain the residues of cooked plants. The fact that Congo Red stains cellulose is also useful, because cellulose can often be difficult to distinguish microscopically from residues such as bone collagen fibres.

\section{Further Work}

There are a number of studies that should preferably be done to support the use of Congo Red staining of archaeological residues. Firstly, further taphonomic studies should be completed, looking specifically at whether cooked starch grains are preserved and under what circumstances, and whether their deposition for archaeological time spans changes their structure or appearance. Secondly, a reference collection should be compiled with samples of archaeological and experimental cooked starches. Experimental samples should be obtained from as many different starch species as possible, and controlled experiments should be conducted on species of different sizes, using a variety of cooking temperatures and cooking times, and different methods of cooking and processing. Thirdly, examining the use-wear on tools with residues stained with Congo Red should be undertaken to determine whether the evidence for processing of either cooked or raw starchy plants is in accordance with the conclusions drawn from residue analysis and staining.

\section{Acknowledgements}

Thanks to: the late Dr Tom Loy, formerly of the School of Social Science, University of Queensland for supervision and collaboration in developing the method; Dr Sean Ulm, Aboriginal and Torres Strait Islander Studies Unit, University of Queensland; Dr Richard Robins, Everick Heritage Consulting; Eastern Yugambeh Limited; Nathan Woolford, Aboriginal and Torres Strait Islander Studies Unit, University of Queensland; Sue Nugent, Alison Crowther, Michael Haslam, Meg Heaslop, Luke Kirkwood and Dr Gail Robinson, School of Social Science, University of Queensland; and Environmental Resources Management (Australia) Pty Ltd. 


\section{References}

Babot, M. 2003. Starch grain damage as an indicator of food processing. Terra Australis 19. Canberra: ANU E Press.

Badenhuizen, N. P. 1965. Occurrence and development of starch in plants. In R. L. Whistler and E. F. Paschall (eds), Starch chemistry and technology Volume 1: Fundamental aspects, pp 65-103. New York: Academic Press.

Banfield, E. J. 1908. The Confessions of a beachcomber. St Lucia: University of Queensland Press.

Banks, W. and C. T. Greenwood. 1975. Starch and its components. Edinburgh: University Press.

Barton, H., R. Torrence and R. Fullagar. 1998. Clues to stone tool function re-examined: Comparing starch grain frequencies on used and unused obsidian artefacts. Journal of Archaeological Science 25:1231-1238.

Beck, W., A. Clarke and L. Head. 1989. Plants in hunter-gatherer archaeology. In W. Beck, A. Clarke and L. Head (eds), Plants in Australian archaeology, pp 1-13. St Lucia: Anthropology Museum, University of Queensland. Tempus 1.

Brand, J. C. and V. Cherikoff. 1985. The nutritional composition of Australian Aboriginal food plants of the desert regions. In G. E. Wickens, J. R. Goodin and D. V. Field (eds), Plants for arid lands, pp 53-69. London: George Allen and Unwin.

Brown, G. R. 1893. Notes on the uses, etc., of some native plants in the Port Macquarie district. Agricultural Gazette of New South Wales 4(9):680-682.

Canti, M. G. 1998. The micromorphological identification of faecal spherulites from archaeological and modern materials. Journal of Archaeological Science 25:432-444.

Chou, K.-S., J.-C. Tsai and C.-T. Lo. 2001. The adsorption of Congo Red and vacuum pump oil by rice hull ash. Bioresource Technology 78(2):217-219.

Conn, H. J. and R. D. Lillie. 1969. H. J. Conn's biological stains: A handbook on the nature and uses of the dyes employed in the biological laboratory, 8th edn. Baltimore: The Williams and Wilkins Company.

Cortella, A. R. and M. L. Pochettino. 1994. Starch grain analysis as a microscopic diagnostic feature in the identification of plant material. Economic Botany 48(2):171-181.

Fullagar, R. 1998. Use-wear, residues and lithic technology. In R. Fullagar (ed.), A closer look: Recent Australian studies of stone tools, pp 13-17. Sydney: Archaeological Computing Laboratory, School of Archaeology, University of Sydney. Sydney University Archaeological Methods Series 6.

Gould, R. A. 1969. Yiwara: Foragers of the Australian desert. New York: Scribner.

Hall, J., S. Higgins and R. Fullagar. 1989. Plant residues on stone tools. In W. Beck, A. Clarke and L. Head (eds), Plants in Australian archaeology, pp 136-160. St Lucia: Anthropology Museum, University of Queensland. Tempus 1.

Hather, J. G. 1991. The identification of charred archaeological remains of vegetative parenchymous tissue. Journal of Archaeological Science 18:661-675.

Kaberry, P. M. 1935. The Forrest River and Lyne River tribes of north-west Australia: A report on field work. Oceania 5:408-436.

Khurana, R., V. N. Uversky, L. Nielson, and A. L. Fink. 2001. Is Congo Red an amyloid-specific dye? Journal of Biological Chemistry 276(25):22715-22721.

Lamb, J. 2003. The raw and the cooked: A study on the effects of cooking on three Aboriginal plant foods from southeast Queensland. Unpublished BA (Hons) thesis. Department of Anthropology, Archaeology and Sociology, School of Social Science, University of Queensland, St Lucia.

Lamb, J. and T. H. Loy. 2005. Seeing red: The use of Congo Red dye to identify cooked and damaged starch grains in archaeological residues. Journal of Archaeological Science 32:1433-1440.

Latz, P. K. 1995. Bushfires and bushtucker: Aboriginal plant use in Central Australia. Alice Springs: IAD Press. 
Latz, P. K. and G. F. Griffin. 1978. Changes in Aboriginal land management in relation to fire and to food plants in central Australia. In B. S. Hetzel and H. J. Frith (eds), The nutrition of Aborigines in relation to the ecosystem of Central Australia, pp 77-85. Melbourne: CSIRO.

Lee, R. B. 1965. Subsistence ecology of the !Kung Bushmen. Ann Arbor: University Microfilms.

Lee, R. B. 1968. What hunters do for a living, or, how to make out on scarce resources. In R. B. Lee and I. De Vore (eds), Man the hunter, pp 30-48. Chicago: Aldine.

Loy, T. H. 1994. Methods in the analysis of starch residues on prehistoric stone tools. In J. G. Hather (ed.), Tropical archaeobotany: Applications and new developments, pp 86-114. London: Routledge.

Loy, T. H., M. Spriggs and S. Wickler. 1992. Direct evidence for human use of plants 28,000 years ago: Starch residues on stone artefacts from the northern Solomon Islands. Antiquity 66:898-912.

Maiden, J. H. 1900. Native food-plants. Agricultural Gazette of New South Wales 10 (4):279-290.

Meehan, B. 1989. Plant use in a contemporary Aboriginal community and prehistoric implications. In W. Beck, A. Clarke and L. Head (eds), Plants in Australian archaeology, pp 14-30. St Lucia: Anthropology Museum, University of Queensland. Tempus 1.

Mehta, S. and Y. S. Rajput. 1998. A method for staining of proteins in nitrocellulose membrane and acrylamide gel using Congo Red dye. Analytical Biochemistry 263(2):248-251.

Mountford, C. P. 1960. Records of the American-Australian scientific expedition to Arnhem Land. Anthropology and Nutrition, Volume 2. Melbourne: Melbourne University Press.

O'Connell, J. F., P. K. Latz and P. Barnett. 1983. Traditional and modern plant use among the Alyawara of central Australia. Economic Botany 37(1):80-109.

Pearsall, D. M. 2000. Paleoethnobotany: A handbook of procedures, 2nd edn. Sydney: Academic Press.

Peterson, N. 1973. Camp site location among Australian hunter-gatherers: Archaeological and ethnographic evidence for a key determinant. Archaeology and Physical Anthropology in Oceania 8(3):173-193.

Peterson, N. 1978. The traditional pattern of subsistence to 1975. In B. S. Hetzel and H. J. Frith (eds), The Nutrition of Aborigines in relation to the ecosystem of Central Australia, pp 25-35. Melbourne: CSIRO.

Piperno, D. R. and I. Holst. 1998. The presence of starch grains on prehistoric stone tools from the humid neotropics: Indications of early tuber use and agriculture in Panama. Journal of Archaeological Science 25:765-776.

Ramesh, H. P. and R. N. Tharanathan. 1999. Water-extracted polysaccharides of selected cereals and influence of temperature on the extractability of polysaccharides in sorghum. Food Chemistry 64(3):345-350.

Reichert, E. T. 1913. The differentiation and specificity of starches in relation to genera, species, etc.: Stereochemistry applied to protoplasmic processes and products, as a strictly scientific basis for classification of plants and animals. Washington: Carnegie Institute of Washington.

Robins, R., J. Lamb and N. Woolford. 2005. Between swamp and sea: Archaeological investigations of an Aboriginal midden at Allisee Residential Development, Hollywell, Gold Coast Queensland. Consultancy report for Stocklands Pty Ltd for Eastern Yugambeh Ltd.

Roth, W. E. 1901. Food: Its search, capture and preparation. North Queensland Ethnology Bulletin 3:1-31.

Therin, M., R. Fullagar and R. Torrence. 1999. Starch in sediments: A new approach to the study of subsistence and land use in Papua New Guinea. In C. Gosden and J. G. Hather (eds), The prehistory of food: Appetites for change, pp 438-462. London: Routledge.

Thozet, A. 1866. Notes on some of the roots, tubers, bulbs, and fruits, used as vegetable food by the Aboriginals of Northern Queensland, Australia. Rockhampton: W. H. Buzacott, Bulletin Office, Denham Street.

Threlkeld, L. E. 1825. Reminiscences of the Aborigines of New South Wales. In N. Gunson (ed) Australian reminiscences and papers of L. E. Threlkeld, missionary to the Aborigines 1824-1859, pp 41-82.

Canberra: Australian Institute of Aboriginal Studies

Torrence, R. and H. Barton. 2006. Ancient starch research. California: Left Coast Press, Inc. 
Ulm, S. 2006. Coastal themes: An archaeology of the Southern Curtis Coast, Queensland. Terra Australis 24. Canberra: ANU E Press.

Voet, D. and J. G. Voet. 2004. Biochemistry: Biomolecules, mechanisms of enzyme action, and metabolism, Volume 1, third edn. New York: John Wiley \& Sons.

Watkins, G. 1891. Note on the Aborigines of Stradbroke and Moreton Islands. Proceedings of the Royal Society of Queensland 8:40-50. 